(c) American Dairy Science Association, 2004.

\title{
Detection of Milk Mixtures in Halloumi Cheese
}

\author{
I. Recio, M. R. García-Risco, ${ }^{*}$ L. Amigo, E. Molina, M. Ramos, \\ and P. J. Martín-Álvarez \\ Instituto de Fermentaciones Industriales, \\ CSIC. C/ Juan de la Cierva, 3. 28006 Madrid, Spain
}

\section{ABSTRACT}

A capillary electrophoresis method has been applied to the detection of illegal addition of milk from goat and/ or cow in Halloumi cheese, traditionally made with sheep milk. The electrophoretic profiles of the casein from Halloumi cheeses have revealed that caprine para- $\kappa$-casein and bovine $\alpha_{\mathrm{S} 1}$-casein peaks point to the presence of low percentages of goat's and/or cow's milk added to Halloumi cheese. Stepwise multiple linear regression has been used to predict these percentages with a standard error of the estimation of $2.14 \%$. The analytical method combined with the statistical application is valid for the prediction of percentages higher than $2 \%$ of goat's and percentages of 5\% of cow's milk added to the cheese either in fresh or ripened cheese. The standard error of estimation was higher for the prediction of cow's milk than for goat's milk.

(Key words: milk mixture, Halloumi cheese, capillary zone electrophoresis)

Abbreviation key: CE = capillary electrophoresis, $\mathbf{R M S E P}_{\mathbf{C V}}=$ root mean square error of prediction obtained by leave-one-out cross-validation procedure, SMLR = stepwise multiple linear regression.

\section{INTRODUCTION}

Halloumi cheese is traditionally made in Cyprus from sheep milk. It is a semi-hard rindless cheese preserved in brine. The manufacture of Halloumi has been described by Anifantakis and Kaminarides (1983). The most characteristic peculiarity of the manufacture of this cheese is that after separation of the curd, the whey is heated to 80 to $90^{\circ} \mathrm{C}$ for $30 \mathrm{~min}$ to coagulate the whey proteins that are used in the manufacture of Anari (Phelan et al., 1993).

Received July 10, 2003.

Accepted October 28, 2003.

Corresponding author: Mercedes Ramos; e-mail: mramos@ ifi.csic.es.

*Present address: Unidad Asociada de Ciencia y Tecnología de Alimentos UAM-CSIC. Campus de Cantoblanco, 28049, Madrid, Spain.
The detection of milk mixtures from different species in cheeses has been a subject of interest for some time (Ramos and Juárez, 1986). Most of the methods described in the literature are related to the qualitative detection of low quantities of cow's milk in ewe's milk cheeses by different analytical techniques, including electrophoretic techniques (Amigo et al., 1992), chromatographic techniques (de Frutos et al., 1991), Western blotting techniques (Molina et al., 1996), or DNA-based techniques (Plath et al., 1997; Klotz and Einspanier, 2001). There is a reference method for detecting bovine caseins in cheeses made from ovine milk by isoelectric focusing of $\gamma$-CN after plasminolysis (European Commission, 1996), which has been applied to the detection of cow's milk in Halloumi cheese (Kandarakis et al., 1996). Volitaki and Kaminarides (2001) detected 1\% of cow's milk in ovine Halloumi cheese by analysis of $\gamma$-CN after plasminolysis by HPLC, and Kaminarides et al. (1995) detected cow's milk in ovine Halloumi cheese by the analysis of the bovine $\alpha_{\mathrm{S} 1}-\mathrm{CN}$. Nevertheless, to the best of our knowledge, no method to detect goat's milk in Halloumi cheese has been published. The detection of goat's milk in cheeses made from milk other than caprine has been performed by isoelectric focusing of whey proteins (Amigo et al., 1989; Molina et al., 1995) and also by immunological methods using polyclonal (Rodríguez et al., 1994) or monoclonal (Haza et al., 1999) antibodies against goat proteins. Over the last years, capillary electrophoresis has been used to separate and analyze the casein fraction in mixtures of cow's, ewe's, and goat's milk (Molina et al., 1999) and their corresponding cheeses (Cattaneo et al., 1996; Molina et al., 2000). The differences found between the CE patterns of the casein fraction of milk from different species allowed identification and quantitative determination of milk in binary and ternary milk mixtures after the application of a statistical procedure (Molina et al., 1999).

The overall objective of this study was to evaluate a capillary electrophoresis (CE) method to detect goat's and cow's milk in Halloumi cheese at different stages of its ripening process and to enable the prediction of the percentages of caprine and bovine milk employed in the manufacture of Halloumi cheese by using a statistical method for modeling quantitative relationship between 
Table 1. Percentage of milk mixtures (ovine, caprine, and bovine) of the experimental Halloumi cheeses.

\begin{tabular}{lllllllllll}
\hline Cheese trial & 1 & 2 & 3 & 4 & 5 & 6 & 7 & 8 & 9 & 10 \\
\hline Ovine & 100 & 99 & 98 & 95 & 90 & 50 & 0 & 80 & 90 & 70 \\
Caprine & 0 & 1 & 2 & 5 & 10 & 50 & 100 & 10 & 5 & 15 \\
Bovine & 0 & 0 & 0 & 0 & 0 & 0 & 0 & 10 & 5 & 15 \\
\hline
\end{tabular}

a variable and a block of variables as stepwise multiple linear regression (SMLR).

\section{MATERIALS AND METHODS}

\section{Cheese Samples}

Three batches of Halloumi cheese with different percentages of cow's, ewe's, and goat's milk were manufactured in Cyprus, under the responsibility of the Cyprus Milk Industries Organization (CMIO). Samples were taken at $0 \mathrm{~d}$ and after $40 \mathrm{~d}$ of ripening. The composition of each cheese trial is described in Table 1. Samples with code numbers 1 and 7 are pure ovine and caprine cheeses, respectively. Samples with code numbers $2,3,4,5$, and 6 are referred to as binary samples and samples with code numbers 8,9 , and 10 are termed hereafter as ternary samples.

\section{Isolation of Caseins from Cheeses}

Five grams of Halloumi cheese was homogenized with $8 \mathrm{~mL}$ of Milli-Q water (Millipore Corp., Bedford, MA). Casein was obtained by precipitation at $\mathrm{pH} 4.6$ with 1 $M \mathrm{HCl}$, followed by centrifugation at $4500 \times g$ for $20 \mathrm{~min}$. The pellet was washed 3 times with $40 \mathrm{~mL}$ of acidic water (pH 4.6), followed by 2 additional washes with $40 \mathrm{~mL}$ of a mixture 50/50 dichloromethane/acidified water. Finally, the washed pellet was freeze-dried and stored at $-18^{\circ} \mathrm{C}$ until analysis.

Purified ovine, caprine, and bovine para- $\kappa$-CN, previously obtained in our laboratory, were used.

\section{Capillary Electrophoresis}

Capillary electrophoresis analyses of the $\mathrm{CN}$ fractions were performed on a Beckman P/ACE System 2050 (Beckman Instruments Inc., Fullerton, CA) following the method of Recio and Olieman (1996). Separations were carried out at $\mathrm{pH} 3.0$ with a hydrophilic-coated fusedsilica capillary (CElect P1, Supelco, Bellefonte, PA) of $0.67 \mathrm{~m} \times 50 \mu \mathrm{m}$, at a temperature of $45^{\circ} \mathrm{C}$, with a linear voltage gradient of 0 to $25 \mathrm{kV}$ for $3 \mathrm{~min}$, followed by constant voltage of $25 \mathrm{kV}$. Detection was carried on at $214 \mathrm{~nm}$. Each sample was analyzed in duplicate. Peak identification was performed by using isolated protein fractions and according to the identification described by Recio et al. (1997) and Molina et al. (1999).

\section{Statistical Methods}

Stepwise multiple linear regression was used to determine of the percentage of caprine and bovine milk in Halloumi cheeses. A total of 24 variables, the 12 normalized area percentages of the main CE peaks (see Figure 1) and their corresponding square values were considered as possible predictor variables in the predictive model. The normalized areas are calculated by: (normalized peak area $i)=($ peak area of peak $i) /($ migration time of peak $i$ ) and the normalized area percentage of each peak was calculated by making the sum of the 12 peaks considered equal to 100. Values of 4.00 and 3.99 were used for the $F$-statistic to enter and to remove variables, respectively (Martín-Álvarez, 2000). The RMSE of prediction obtained by leave-one-out cross-validation procedure $\left(\mathrm{RMSEP}_{\mathrm{CV}}\right)$ was used as a measure of the ability of the model to furnish accurate predictions (Martens and Naes, 1993). This value can be considered as an approximation of the prediction error and was calculated using the equation:

$$
\left.R M S E P_{\mathrm{cv}}=\left(\sum_{i=1}^{n}\left(c_{i}-\hat{c}_{(i)}\right)^{2} / n\right)\right)^{1 / 2}
$$

where $c_{i}$ is the real percentage of caprine/bovine milk for the $i$ th sample of the Halloumi cheeses, $\hat{c}_{(i)}$ is the predicted percentage of caprine/bovine milk obtained with the model constructed without the $i$ th sample, and $n$ was the number of cheeses used in the estimated predictive model $(\mathrm{n}=21$ for fresh cheeses made of binary milk mixtures; $\mathrm{n}=21$ for ripened cheeses made of binary milk mixtures; $\mathrm{n}=30$ for fresh (or ripened) cheeses considering binary and ternary milk mixtures, $\mathrm{n}=24$ for fresh and ripened cheeses made from ternary milk mixtures, and $\mathrm{n}=60$ when all cheeses are considered).

The STATISTICA program for Windows release 5.1 (StatSoft Inc., 1998. Tulsa, OK, USA) was used for data processing. 


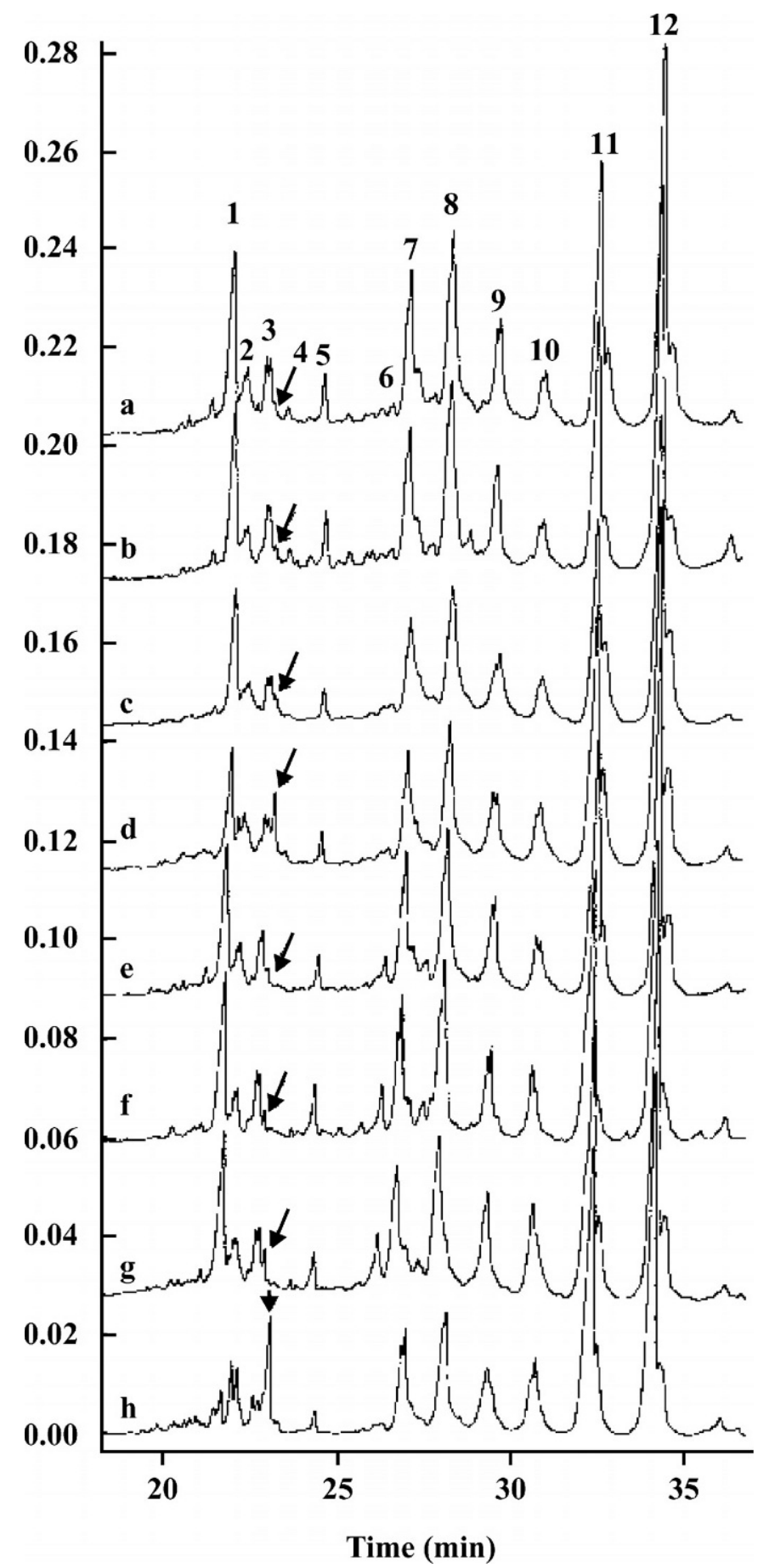

Figure 1. Capillary electropherograms of the casein fraction obtained from fresh Halloumi cheeses made from (a) ovine milk, (b) ovine milk containing $5 \%$ of caprine milk, (c) ovine milk containing $10 \%$ of caprine milk, (d) ovine milk containing $50 \%$ of caprine milk, (e) ovine milk containing $5 \%$ of caprine milk and $5 \%$ of bovine milk, (f) ovine milk containing $10 \%$ of caprine milk and $10 \%$ of bovine milk, (g) ovine milk containing $15 \%$ of caprine milk and $15 \%$ of bovine milk, and (h) caprine milk. 1 , ovine and bovine para- $\kappa$-CN; 2 and 3 , $\alpha_{\mathrm{S} 2}-\mathrm{CN} ; 4$, caprine para- $\kappa$ - $\mathrm{CN} ; 5$, unidentified peaks; 6 , bovine $\alpha_{\mathrm{S}^{-}}$ CN; 7, 8 and 9 , ovine and caprine $\alpha_{\mathrm{S} 1}-\mathrm{CN} ; 10,11$ and $12, \beta$-CN. The arrows indicate the caprine para- $\kappa-\mathrm{CN}$.

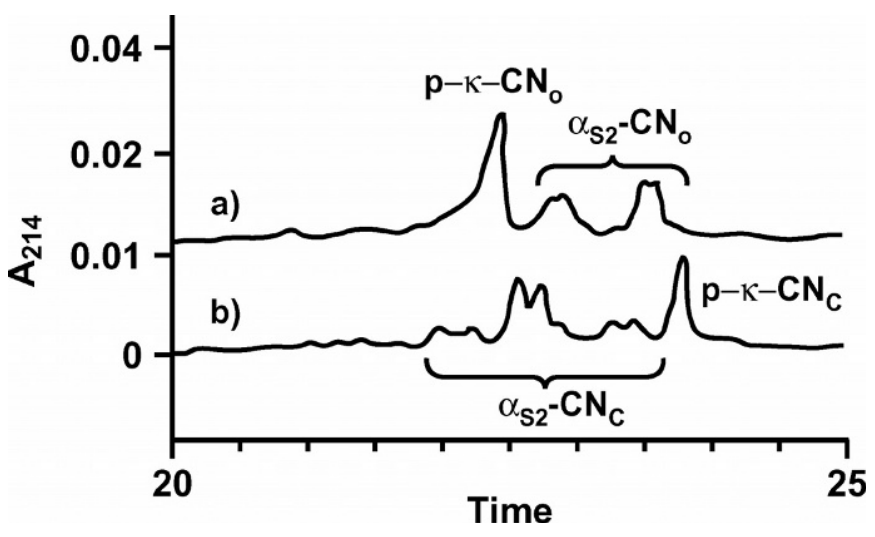

Figure 2. Capillary electropherogram of the casein fraction obtained from fresh Halloumi cheeses made from (a) ovine milk, and (b) caprine milk. Peak identification as in Figure 1.

\section{RESULTS AND DISCUSSION}

\section{Fresh Halloumi Cheeses}

Prediction of caprine milk percentage in binary cheeses. Figure 1 shows the electropherograms of the casein fraction obtained from fresh Halloumi cheeses made from genuine ovine, caprine (Figure $1 \mathrm{a}$ and $\mathrm{h}$ ), binary mixtures containing 5,10 , and $50 \%$ of caprine milk in ovine milk (Figure 1b, c, d). By using this CE method, the main casein fractions from ovine and caprine milk cheeses presented the same migration time except for the para- $\kappa-\mathrm{CN}$, which can be used to identify and quantitate these mixtures (Molina et al., 2000). The ovine para- $\kappa-\mathrm{CN}$ (peak no. 1 in Figure 1) presented the shortest migration time, while the caprine para- $\kappa-\mathrm{CN}$ (peak no. 4 in Figure 1), due to its lower positive charge, presented a longer migration time than ovine para- $\kappa-\mathrm{CN}$. To confirm peak identity, the caprine para- $\kappa$-CN was identified by spiking a Halloumi cheese sample with purified ovine and caprine para- $\kappa-\mathrm{CN}$. Therefore, the presence of caprine para- $\kappa-\mathrm{CN}$, which presented a slightly longer migration time than the ovine $\alpha_{\mathrm{S} 2}-\mathrm{CN}$ fraction can reveal the addition of caprine milk to ovine milk. Although in fresh Halloumi cheeses there are no significant degradation products that interfere in caprine para- $\kappa$-CN quantification, the proximity of the electrophoretic migration of caprine para- $\kappa-\mathrm{CN}$ to the $\alpha_{\mathrm{S} 2}-\mathrm{CN}$ fraction (Figure 2) makes its quantification difficult at caprine milk percentages lower than or equal to $2 \%$ (statistical data not shown). Moreover, the $\alpha_{\mathrm{S} 2}-\mathrm{CN}$ fraction from pure ovine milk cheeses showed a small shoulder with the same migration time as caprine para- $\kappa$-CN. This shoulder was quantified, and its area was assigned to zero percent of caprine milk and considered as such to apply the different regression methods. 
Table 2. Results of the application stepwise multiple linear regression (SMLR) for prediction of the percentages of caprine or bovine milk in Halloumi cheeses. ${ }^{1}$

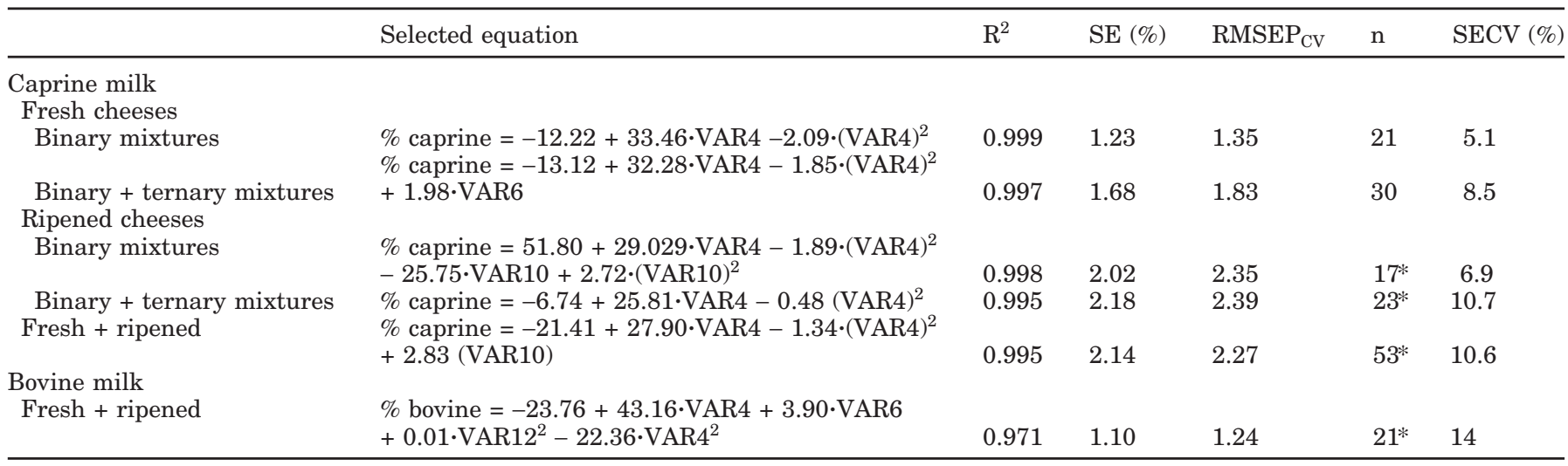

${ }^{1} \mathrm{R}^{2}=$ Determination coefficient; $\mathrm{SE}=$ standard error of estimation; $\mathrm{n}$, number of data points; RMSEP $\mathrm{CV}=$ root mean square error of prediction obtained by leave-one-out cross-validation procedure, SECV = standard error of estimation calculated as percentage of the mean value of percentage of caprine/bovine milk; VAR4 = normalized area percentage of the caprine para- $\kappa$-CN peak; VAR6 = normalized area percentage of the bovine $\alpha_{\mathrm{S} 1}$-CN; VAR10 and VAR12 = normalized area percentage of the ovine $\beta$-CN peaks. *Some of the samples were discarded as they showed "abnormal" profiles.

To generate a model that could enable the prediction of the caprine milk percentage in ovine cheeses, the behavior of each variable (named after the same number as the corresponding peak in Figure 1, i.e., VAR1 = ovine para- $\kappa-\mathrm{CN}$ to VAR12 = ovine and caprine $\beta$-CN) was initially studied by plotting it against the caprine milk percentage of the cheeses. The variables that best fit possible theoretical curves were ovine and caprine para$\kappa$-CN. To select the best variables for prediction of caprine milk percentages in fresh binary Halloumi cheeses (samples 1 to 7), we used SMLR with all 24 defined predictor variables. The variables selected for the predictive model (Table 2) were VAR4 and (VAR4) ${ }^{2}$, i.e., caprine para- $\kappa$ $\mathrm{CN}$ area and its square value, and these two variables explained more than $99 \%$ of the variation in caprine milk percentages in binary fresh Halloumi cheeses $\left(\mathrm{R}^{2}=\right.$ 0.999 ). The standard error was $1.23 \%$ corresponding to $5.1 \%$ of the mean value of the dependent variable. As expected, the normalized area of the peak corresponding to caprine para- $\kappa$-CN showed a positive relationship with the percentage of caprine milk. The procedure employed for Halloumi cheese manufacture does not preclude caprine para- $\kappa-\mathrm{CN}$ quantification in fresh cheeses, and, therefore, this protein fraction can be used as an indicator of the addition of caprine milk to ovine cheese milk. A good agreement was obtained between the observed and predicted percentages of caprine milk in the fresh cheeses using this model, the highest residual value was $3.2 \%$ corresponding to a sample containing $10 \%$ of caprine milk in ovine milk, for which the model predicted a percentage of $13.2 \%$ of goats' milk. It should also be noted that the model exhibits good behavior at low caprine milk percentages, avoiding false-positive results. All the samples of pure ovine milk showed negative or very low $(<0.5 \%)$ predicted results. These results and the low $\mathrm{RMSEP}_{\mathrm{CV}}$ value $(1.35 \%)$ showed the good prediction behavior of the model.

Prediction of caprine milk percentage in binary and ternary milk mixtures. The SMLR was also used to determine the percentages of caprine milk in all fresh, binary and ternary, Halloumi cheeses. The selected variables, from the 24 possible candidates, were VAR4 (caprine para- $\kappa$-CN area), its square value $\left(\mathrm{VAR} 4^{2}\right.$ ), and VAR6 (bovine $\alpha_{\mathrm{S} 1^{-}} \mathrm{CN}$ ). Peak 6 corresponds to bovine $\alpha_{\mathrm{S}^{-}}$ $\mathrm{CN}$, and comigrates with another unidentified peak from goat's and ewe's milk. However, it has been verified that the addition of bovine milk can be clearly detected by the increase in the area of peak 6 . These variables (VAR4, $\mathrm{VAR}^{2}$, and VAR6) explain more than $99 \%$ of the variation in caprine milk percentages in all fresh Halloumi cheeses, taking into account the binary and ternary milk mixtures for the statistical analyses $\left(R^{2}=0.997\right)$ (Table 2). The SE was $1.68 \%$ (a $8.5 \%$ of the relative error) and the $\mathrm{RMSEP}_{\mathrm{CV}}$ was $1.83 \%$. The fit for the predicted percentage of caprine milk in these cheeses was good, as shown by the high value of $\mathrm{R}^{2}$ and the low value of RMSEP $_{\mathrm{CV}}$.

\section{0-Day-Old Halloumi Cheeses}

Although some proteolysis products were found, casein degradation was not extreme, and the main casein fractions could be separated and quantified. Of special interest was the separation of the caprine para- $\kappa$ - $\mathrm{CN}$ fraction from the ovine $\alpha_{\mathrm{S} 2^{-}} \mathrm{CN}$, since the detection of caprine milk addition is based on this. The para- $\kappa-\mathrm{CN}$ fraction remains intact during ripening (Addeo et al., 1990) and no proteolysis product was found interfering with the caprine para- 
$\kappa$-CN quantification. Therefore, as occurs in fresh cheeses, this electrophoretic peak can be used as an indicator of the presence of added caprine milk. This fraction has also been used to determine by cation-exchange HPLC the percentages of cow's, ewe's, and goat's milk in model Camembert cheeses at different ripening stages (Mayer et al., 1997).

The results of the application of SMLR to the prediction of the percentage of caprine milk in binary and in binary and ternary mixtures are summarized in Table 2 . In the case of binary mixtures, the selected variables (VAR4, caprine para- $\kappa$-CN, VAR10, $\beta$-CN fraction, and their square values $\mathrm{VAR}^{2}$ and VAR $10^{2}$ ) explain more than $99 \%$ of the variation of the caprine milk percentages in ripened binary Halloumi cheeses $\left(R^{2}=0.998\right)$. The SE was $2.02 \%$ and the RMSEP $\mathrm{CV}_{\text {was }} 2.38$. For binary and ternary mixtures the selected variables were VAR4 and its square value. The determination coefficient $\left(\mathrm{R}^{2}=\right.$ 0.995), the standard error of the estimation $(\mathrm{SE}=2.18 \%$ ) and the RMSEP $_{\mathrm{CV}}(2.39)$ were comparable to those calculated for fresh ternary cheeses.

\section{Prediction of Caprine and Bovine Milk Percentage in Halloumi Cheese (Independent of the Binary or Ternary Milk Mixture and Its Ripening Stage)}

As expected, the variables selected after the application of SMLR for prediction of the percentages of caprine milk in all fresh and ripened cheeses from the 24 possible candidates (the 12 normalized peak percentages obtained from the CE profile and their squares) were VAR4 (caprine para- $\kappa-\mathrm{CN}$ area), its square value $\left(\mathrm{VAR}^{2}\right)$, and VAR10 ( $\beta$-CN fraction) (Table 2 ). These variables explained more than $99 \%$ of the variation of the caprine milk percentages in fresh and ripened binary Halloumi cheeses. The SE was 2.14 (10.6\% of relative error), and the fit for the prediction of the percentage of caprine milk in these cheeses was good, as shown by the high value of $R^{2}(0.995)$ and the low value of $\operatorname{RMSEP}_{\mathrm{CV}}(2.27 \%)$.

Moreover, the prediction of bovine milk percentage in fresh and ripened Halloumi cheeses was also performed. Figure 1 (electropherograms e, f, and g) shows the electrophoretic patterns corresponding to different percentages of caprine, ovine, and bovine milk. If the addition of caprine milk to ovine Halloumi cheese can be detected by the presence of caprine para- $\kappa-\mathrm{CN}$, the addition of bovine milk resulted in an increase of the peak, which precedes the ovine $\alpha_{\mathrm{S} 1}-\mathrm{CN}$ fraction. This peak corresponded to bovine $\alpha_{\mathrm{S} 1}-\mathrm{CN}$ that shows shorter migration time than the ovine fraction due to its higher isoelectric point. The fitted equation for the prediction of the percentages of bovine milk in fresh and ripened Halloumi cheeses (samples 1, 8, 9, and 10 in Table 1) from the normalized peak percentages obtained from the CE profile using SMLR is shown in Table 2. The selected variables were: VAR4, VAR6, (VAR4) ${ }^{2}$, and $(\mathrm{VAR} 12)^{2}$ with a $\mathrm{R}^{2}$ of $97.1 \%$ a SE of $1.1 \%$ and a RMSEP $_{\mathrm{CV}}$ of $1.24 \%$.

The prediction ranges of the percentages of goat's and cow's milk taken from the residual values of the proposed models (Table 2) are shown in Table 3 . The prediction of 1 and $2 \%$ of caprine milk gives rise to ranges of up to 4.21 and $6.28 \%$, respectively, because of the difficulties in quantifying the corresponding peaks. In any case, the electropherogram is clear enough to know for certain that the product has been adulterated. If the exact percentage of adulterated milk must be determined, more sensitive methods should be applied. On the other hand, the prediction of percentages $\geq 5 \%$ (for goats and cows milk) is attained within a narrow range, considering that the model is including percentages ranging from 1 to $100 \%$. In general, as seen in this table if there is some doubt about a Halloumi cheese sample, and its maturation time

Table 3. Range of predicted values for caprine and bovine milk in Halloumi cheeses from the models in Table 2, considering all the cheeses studied. $\mathrm{O}=$ ovine, $\mathrm{C}=$ caprine, and $\mathrm{B}=$ bovine.

\begin{tabular}{|c|c|c|c|c|c|c|}
\hline \multirow{2}{*}{$\begin{array}{l}\text { Sample } \mathrm{n}^{\circ} \\
\text { and \% of } \\
\mathrm{O} / \mathrm{C} / \mathrm{B} \\
\text { milk }\end{array}$} & \multicolumn{3}{|c|}{$\begin{array}{c}\text { Detection of caprine milk in Halloumi cheese } \\
\% \text { caprine }=-21.41+27.90 \cdot \text { VAR } 4 \\
-1.34 \cdot(\text { VAR } 4)^{2}+2.83(\text { VAR10 })\end{array}$} & \multicolumn{3}{|c|}{$\begin{array}{l}\text { Detection of bovine milk in } \\
\text { Halloumi cheese } \% \text { bovine }= \\
-23.76+43.16 \cdot \text { VAR } 4+3.90 \cdot \text { VAR } 6 \\
+0.01 \cdot{\text { VAR } 12^{2}-22.36 \cdot \text { VAR }^{2}}^{2}\end{array}$} \\
\hline & $\begin{array}{l}\text { Observed } \\
\text { value }\end{array}$ & $\begin{array}{l}\text { Mean of the } \\
\text { predicted } \\
\text { values }\end{array}$ & $\begin{array}{l}\text { Range of } \\
\text { prediction }\end{array}$ & $\begin{array}{l}\text { Observed } \\
\text { value }\end{array}$ & $\begin{array}{l}\text { Mean of the } \\
\text { predicted } \\
\text { values }\end{array}$ & $\begin{array}{l}\text { Range of } \\
\text { prediction }\end{array}$ \\
\hline 1. $100 / 0 / 0$ & 0 & 0.22 & $(-0.76)-1.2$ & 0 & 0.30 & $(-0.25)-0.85$ \\
\hline 2. $99 / 1 / 0$ & 1 & 2.60 & $0.99-4.21$ & & & \\
\hline 3. $98 / 2 / 0$ & 2 & 4.14 & $2.00-6.28$ & & & \\
\hline 4. $95 / 5 / 0$ & 5 & 5.52 & $4.42-6.62$ & & & \\
\hline 5. $90 / 10 / 0$ & 10 & 9.47 & $8.03-10.93$ & & & \\
\hline 6. $50 / 50 / 0$ & 50 & 50.16 & $48.11-52.21$ & & & \\
\hline 7. $0 / 100 / 0$ & 100 & 99.74 & $98.52-100.96$ & & & \\
\hline 8. $80 / 10 / 10$ & 10 & 7.09 & $4.19-9.99$ & 10 & 9.88 & $9.19-10.57$ \\
\hline 9. $90 / 5 / 5$ & 5 & 3.81 & $1.71-5.91$ & 5 & 4.10 & $3.15-5.05$ \\
\hline 10. $70 / 15 / 15$ & 15 & 13.11 & $11.43-14.79$ & 15 & 14.85 & $13.94-15.76$ \\
\hline
\end{tabular}


and its milk composition is unknown, the procedure proposed in this work allows a very accurate prediction of the presence of caprine and bovine milk in binary and ternary samples. Moreover, these ranges of prediction become lower if some information about the cheese is available, i.e., if the cheese is fresh or ripened or if the suspicion concerns the addition of caprine milk.

\section{CONCLUSIONS}

The proposed CE method allows the detection of added caprine and bovine milk to ovine Halloumi cheese by using the caprine para- $\kappa-\mathrm{CN}$ and the bovine $\alpha_{\mathrm{S} 1}-\mathrm{CN}$ as indicators from caprine and bovine milk, respectively. The quantification of low percentages of caprine milk $(\leq 2 \%)$ is difficult due to the incomplete resolution between caprine para- $\kappa$-CN and ovine $\alpha_{\mathrm{s} 2}-\mathrm{CN}$. However, the application of SMLR allows an acceptable prediction even at low caprine milk percentages in both fresh and ripened cheeses. The standard error of the estimation using all samples was of $2.14 \%$ and RMSEP $\mathrm{CV}$ of $2.27 \%$. The statistical models proposed for bovine milk prediction also presented an acceptable behavior in fresh and ripened cheeses.

The manufacturing process of Halloumi cheese does not affect to caprine para- $\kappa$-CN detection or quantification since the results obtained for milk mixtures are comparable to those obtained for fresh Halloumi cheeses. The ripening time (up to $40 \mathrm{~d}$ ) does not affect the prediction of the caprine milk content, although the standard error of estimation are slightly higher (values of 2.02 and 2.18) than those obtained for fresh samples (values of 1.23 and 1.68).

\section{ACKNOWLEDGMENTS}

The authors wish to thank CMIO the economical support for this work and for providing the cheese samples and G. Psathas for helpful collaboration. We also acknowledge C. Talavera for technical assistance.

\section{REFERENCES}

Addeo, F., L. Moio, L. Chianese, and C. Stingo. 1990. Improved procedure for detecting bovine and ovine milk mixtures in cheese by isoelectric focusing of para- $\kappa$-casein. Milchwissenschaft 45:4-7.

Amigo, L., I. Ibáñez, C. Fernández, G. Santa-María, and M. Ramos. 1989. Comparison of an electrophoretic and an immunological method for the determination of goat and cow milk in cheese. Milchwissenschaft 44:215-218.

Amigo, L., M. Ramos, L. Calhau, and M. Barbosa. 1992. Comparison of electrophoresis, isoelectric focusing, and immunodifussion in determination of cow's and goats's milk in Serra da Estrela cheeses. Lait 72:95-101.
Anifantakis, E. M., and S. E. Kaminarides. 1983. Contribution to the study of Halloumi cheese made from sheep's milk. Aust. J. Dairy Technol. 38:29-31.

Cattaneo, T. M. P., F. Nigro, and G. F. Greppi. 1996. Analysis of cow, goat and ewe milk mixtures by capillary zone electrophoresis $(\mathrm{CE})$ : Preliminary approach. Milchwissenschaft 51:616-632.

de Frutos, M., A. Cifuentes, J. C. Díez-Masa, L. Amigo, and M. Ramos. 1991. Application of HPLC for the detection of proteins in whey mixtures from different animal species. J. HRCC 41:289-295.

European Commission. 1996. Regulation no. 1081/96. Reference method for the detection of cows' milk and caseinate in cheeses from ewes' milk, goats' milk and buffaloes' milk or mixtures of ewes', goats', and buffaloes' milk. OJEC L142:15-25.

Haza, A. I., P. Morales, R. Martín, T. García, G. Anguita, B. Sanz, and P. E. Hernández. 1999. Detection and quantification of goat's cheese in ewe's cheese using a monoclonal antibody and two ELISA formats. J. Sci. Food Agric. 79:1043-1047.

Kaminarides, S., I. Kandarakis, and E. Moschopoulou. 1995. Detection of bovine milk in ovine Halloumi cheese by electrophoresis of $\alpha_{\mathrm{S}^{-}}$ caseins. Aust. J. Dairy Technol. 50:58-61.

Kandarakis, I., S. Kaminarides, and E. Moschopoulou. 1996. Detection of bovine caseins in ovine Halloumi cheese by electrophoresis of para- $\kappa$-caseins and isoelectric-focusing of $\gamma$-caseins. Page 321 in Production and Utilization of Ewe and Goat Milk. IDF/FIL-9603.

Klotz, A., and R. Einspanier. 2001. Development of a DNA-based screening method to detect cow milk in ewe, goat and buffalo milk and dairy products using PCR-LCR-EIA-technique. Milchwissenschaft 56:67-70.

Martens, H., and T. Naes. 1993. Multivariate Calibration. John Wiley \& Sons, Chichester, UK.

Martín-Alvarez, P. J. 2000. Quimiometría Alimentaria. UAM Ediciones, Madrid, Spain.

Mayer, H. K., D. Heidler, and C. Rockenbauer. 1997. Determination of the percentages of cows', ewes', and goats' milk in cheese by isoelectric focusing and cation-exchange HPLC of $\gamma$ - and para- $\kappa$ caseins. Int. Dairy J. 7:619-628.

Molina E., A. Fernández-Fournier, M. de Frutos, and M. Ramos. 1996 Western blotting of native and denatured bovine $\beta$-lactoglobulin to detect addition of cows' milk in cheeses. J. Dairy Sci. 79:191-197.

Molina E., M. de Frutos, and M. Ramos. 2000. Capillary electrophoresis characterization of the casein fraction of cheeses made from cows', ewes' and goats' milks. J. Dairy Res. 67:209-216.

Molina, E., P. J. Martín-Álvarez, and M. Ramos. 1999. Analysis of cows', ewes' and goats' milk mixtures by capillary electrophoresis: Quantification by multivariate regression analysis. Int. Dairy J. 9:99-105.

Molina, E., M. Ramos, and P. J. Martín-Álvarez. 1995. Prediction of the percentages of cows', goats', and ewes' milk in Ibérico cheese by electrophoretic analysis of whey proteins. Z. Lebensm. Unters. Forsch. 201:331-335.

Phelan, J. A., J. Renaud, and P. F Fox. 1993. Some non-european cheese varieties. Pages 421-465 in Cheese: Chemistry, Physics, and Microbiology. Vol. 2. P. F. Fox, ed. Chapman and Hall, London, UK.

Plath, A., I. Krause, and R. Einspanier. 1997. Species identification in dairy products by three different DNA-based techniques. Z. Lebensm. Unters. Forsch. 205:437-441.

Ramos, M., and M. Juárez. 1986. Chromatographic, electrophoretic and immunological methods for detecting mixtures of milk from different species. Int. Dairy Fed. Bull. Doc. 202:175-190.

Recio, I., L. Amigo, M. Ramos, and R. López-Fandiño. 1997. Application of capillary electrophoresis to the study of proteolysis of caseins. J. Dairy Res. 64:221-230.

Recio, I., and C. Olieman. 1996. Determination of denatured serum proteins in the casein fraction of heat-treated milk by capillary zone electrophoresis. Electrophoresis 17:1228-1233.

Rodríguez, E., R. Martín, T. García, P. Morales, I. Gonzales, B. Sanz, and P. E. Hernández. 1994. Sandwich ELISA for detection of goats' milk in ewes' milk and cheese. Food Agric. Immunol. 6:105-111.

Volitaki, A. J., and S. E. Kaminarides. 2001. Detection of bovine milk in ovine Halloumi cheese by HPLC analysis of cheese caseins hydrolysed by plasmin. Milchwissenschaft 56:207-210. 